\title{
Preface to the Special Issue on the Biology and Evolution of Language
}

\author{
W. Tecumseh Fitch ${ }^{1}$
}

Published online: 1 July 2016

(C) Psychonomic Society, Inc. 2016

Language is one of the most distinctive and unusual traits of our species, so it comes as no surprise that humans have speculated about the origins of language since the beginning of written history (and probably long before). These speculations initially took the form of quasi-religious origin myths, but by the time of the Enlightenment at least some ideas had morphed into more concrete hypotheses about how language might have evolved (e.g., Condillac's gestural origins theory), a historical maturation process that has continued into the present day.

Today, the evolution of language has become a fascinating, highly interdisciplinary, and empirically challenging field of scientific research, one that has attracted ever-increasing attention during the past two decades. Since 1996, it has benefited from a dedicated conference (EvoLang: the International Conference on the Evolution of Language) and since 2016 a dedicated journal (the Journal of Language Evolution, published by Oxford University Press). Although these and other venues have helped to generate and to publicize a considerable amount of relevant empirical research, the field remains plagued by an unfortunate but persistent belief that scientific work on the topic of language evolution is inherently and irredeemably speculative.

This prejudice is unjustified: many other branches of science (e.g., geology or cosmology) study complex historical processes, buried in the past, but this does not stop researchers from developing, debating, and testing hypotheses and ultimately

W. Tecumseh Fitch

tecumseh.fitch@univie.ac.at

1 University of Vienna, Vienna, Austria reaching scientific agreement on the basis of converging evidence (e.g., concerning plate tectonics or the Big Bang).

The scientific study of the biology and evolution of language has likewise grown increasingly sophisticated on many fronts, both empirical and theoretical, in the past few decades. Key progress includes fundamental advances in our understanding of the cognitive, linguistic, and biological foundations on which any substantive deductions and inferences about language evolution must rest. Furthermore, the data flooding from these multiple sources has prompted theorists to propose more and more detailed hypotheses about how, when, and why our species developed our unique capacity to acquire language. The field increasingly is permeated by explicit hypotheses that make testable predictions and thus appears primed for substantial progress.

The purpose of the current special issue is to summarize this body of recent research and theory and to bring it to the attention of empirically minded psychologists. The format is mainly based on short opinion and/or review pieces by noted experts in the field that make a few key points, provide a concise overview of a topic area, or propose or develop a hypothesis, in an easily digestible manner. These experts were chosen specifically for their combination of important recent contributions and empirical rigor (virtually all have made key contributions to the discipline in the past 10 years). The special issue also includes an introduction to the field by Tecumseh Fitch and a target article by Simon Kirby, together with multiple short commentaries.

It is the hope of both editor and authors that this assemblage of rigorous work will bring the excitement of, and advances in, this field to a new audience and serve as a snapshot of current thinking and knowledge that will help to spur further 
progress. We also hope that, when taken together, the pieces in this issue will bury forever the idea that this entire research field is limited to speculation and fairy tales.

Authors who have submitted articles for the special issue are listed in alphabetical order (first authors only): Michael Arbib, Cedric Boeckx, Richard Byrne, Dorothy Cheney, Noam Chomsky, Bart de Boer, Ghislaine Dehaene-Lambertz, Merlin Donald, Robin Dunbar,
Olga Feher, Julia Fischer, Simon Fisher, Tecumseh Fitch, Angela Friederici, Susan Goldin-Meadow, Peter Hagoort, Greg Hickok, Dieter Hillert, Ray Jackendoff, Mark Johnson, Adam Kendon, Kevin Laland, John Locke, Heidi Lyn, Kazuo Okanoya, Mark Pagel, Aniruddh Patel, Amy Perfors, Irene Pepperberg, Robert Provine, Thom Scott-Phillips, Ann Senghas, Luc Steels, Ian Tattersall, Carel ten Cate, and Sonja Vernes. 